\title{
Eating and weight disorders: studies on anorexia, bulimia, and obesity turns 19
}

\author{
Massimo Cuzzolaro
}

Published online: 9 February 2014

(c) Springer International Publishing Switzerland 2014

The first issue of Eating and Weight Disorders appeared in 1996. Starting with 2013 the Journal is published by Springer International Publishing and Professor Lorenzo Maria Donini is the precious Co-Editor.

$E W D$ is the official organ of the Italian Society for the Study of Eating Disorders (SIS-DCA: http://sisdcadis turbialimentari.weebly.com) and, as from 2014, of the Italian Society of Obesity (SIO: http://www.sio-obesita. org) which I would really like to welcome. SIO will enhance the attention of $E W D$ to the multifaceted aspects of obesity.

$E W D$ is entering adulthood and its mission remains unchanged. The affiliations mirror the aims of the Journal, devoted to move toward a model of shared knowledge. Therefore, the focus continues to be both on every single eating and weight disorder and on the numberless intersections that link together unhealthy eating behavior, body image, adiposity, metabolism, and nutrition.

At one end of the weight continuum is anorexia nervosa, while obesity is at the other end. According to current taxonomies [1, 2], eating disorders are classified as psychiatric problems whereas obesity is classified as a general medical condition. However, connections and overlaps between the two fields are so relevant that it is not groundless to keep talking about them as "two sides of the same coin" [3-5] and to use wide-ranging expressions like non-homeostatic eating disorders or weight-related disorders.

During the past year, on May 18, the fifth edition of the Diagnostic and Statistical Manual of Mental Disorders (DSM-5) was released by the American Psychiatric

M. Cuzzolaro $(\square)$

via Fedi 12. 57021, Campiglia Marittima, Italy

e-mail: massimo.cuzzolaro@gmail.com
Association (APA) and the chapter on "Feeding and Eating Disorders" included several changes: changes to anorexia nervosa and bulimia nervosa diagnostic criteria; emphases on degrees of severity; addition of binge eating disorder; shift to this chapter of three disorders (pica, rumination disorder, and avoidant/restrictive food intake disorder) that were contained within the DSM-IV-TR chapter "Disorders Usually First Diagnosed in Infancy, Childhood, or Adolescence". By the way, DSM-5 no longer has a childhood disorders chapter.

The DSM is only one of the possible methods of classification of mental disorders, but, since the publication of its third edition (1980), the APA taxonomy has become dominant. In actual fact, DSM-5 is controversial. It breeds checklist diagnoses that are more reliable than valid. In particular, its scheme for classifying feeding and eating disorders is not sufficiently rooted in clinical reality, is not clustered by causal perspective, offers reliable definitions but no way of making sense of symptoms, and is of modest value to clinicians.

As regards eating disorders, the major change in DSM-5 was the official recognition of Binge Eating Disorder (BED) as a specific diagnostic category. Beginning from the last decade of the twentieth century, BED has connected the psychiatric field of eating disorders with the medical area of obesity. The bridge drew more attention to the psychological and psychiatric aspects of obesity and contributed to the development of a multidimensional team approach to the assessment and treatment of eating and weight disorders.

What about obesity? Touching another debated problem, in June 2013 the American Medical Association (AMA) House of Delegates officially declared that obesity is a disease per se and requires treatment. As a matter of fact, two basic questions such as "what is obesity" and 
"how can we reliably define a patient as obese" remain still unanswered. Very likely, considering obesity as a homogeneous condition is incorrect and, in my opinion, it would be preferable to use the term in the plural, obesities. In addition, should obesity be considered not only as a metabolic disorder but also as a mental/brain disorder characterized by compulsive consumption of food and the inability to restrain from eating despite the desire to do so? Neither obesity nor simple overeating was included in DSM-5. In any case, obesity presents high levels of psychiatric comorbidity and, conversely, the prevalence of obesity is very high in people diagnosed as having a mental illness. Finally, one area of research receiving a great deal of attention is the large neurobiological overlap between addiction and some types of obesity.

Getting back to EWD, 62 new articles coming from 23 different countries were published in 2013. Cross-diagnostic problems were the main topic in very many studies. Furthermore, more than one-third of them dealt with various obesity issues.

Together with the co-editor Lorenzo Donini I wish to thank all our readers, contributing authors, and the editorial office for their support and continue to seek their advice and work to serve the needs of clinicians and researchers.

I am particularly grateful to EWD excellent reviewers. Their work plays a vital role in the journal and provides a great educational service. An accurate review is able to turn a manuscript with a good idea into a significant contribution to scientific knowledge.
In 1584, in De l'infinito, universo e mondi, Giordano Bruno wrote: "... il suo desìo consiste più in imparare che in insegnare ...". A Authors, reviewers, board, and editors of a scientific journal should share the same desire to learn by teaching.

We look forward to experiencing continued growth.

Conflict of interest Massimo Cuzzolaro declares he has no conflict of interest.

\section{References}

1. American Psychiatric Association (2013) Diagnostic and statistical manual of mental disorders, DSM-5, 5th edn. American Psychiatric Publishing, Arlington

2. World Health Organization (2010) International statistical classification of diseases and related health problems, 10th revision. Version 2010. World Health Organization, Geneva. 7 Jan 2014. Available from: http://apps.who.int/classifications/icd10/browse/ 2010/en

3. Neumark-Sztainer D (2009) The interface between the eating disorders and obesity fields: moving toward a model of shared knowledge and collaboration. Eat Weight Disord 14(1):51-58

4. Day J, Ternouth A, Collier DA (2009) Eating disorders and obesity: two sides of the same coin? Epidemiol Psichiatr Soc 18(2):96-100

5. Krug I, Villarejo C, Jimenez-Murcia S, Perpina C, Vilarrasa N, Granero R et al (2013) Eating-related environmental factors in underweight eating disorders and obesity: are there common vulnerabilities during childhood and early adolescence? Eur Eat Disord Rev 21(3):202-208

\footnotetext{
${ }^{1}$ He desires more to learn than to teach.
} 